\title{
A Review on Mechanical Properties of Natural Fiber Reinforced Hybrid Polymer Composites
}

\author{
K. P. Ashik, Ramesh S. Sharma \\ R \& D Center, Department of Mechanical Engineering, R.V. College of Engineering, Bangalore, India \\ Email: ashikkallare@gmail.com
}

Received 12 July 2015; accepted 18 September 2015; published 21 September 2015

Copyright (C) 2015 by authors and Scientific Research Publishing Inc.

This work is licensed under the Creative Commons Attribution International License (CC BY). http://creativecommons.org/licenses/by/4.0/ c) (7) Open Access

\begin{abstract}
Natural fibres will take a major role in the emerging "green" economy based on energy efficiency, the use of renewable materials in polymer products, industrial processes that reduce carbon emissions and recyclable materials that minimize waste. Natural fibres are a kind of renewable resources, which have been renewed by nature and human ingenuity for thousands of years. They are also carbon neutral; they absorb the equal amount of carbon dioxide they produce. These fibers are completely renewable, environmental friendly, high specific strength, non-abrasive, low cost, and bio-degradability. Due to these characteristics, natural fibers have recently become attractive to researchers and scientists as an alternative method for fibers reinforced composites. This review paper summarized the history of natural fibers and its applications. Also, this paper focused on different properties of natural fibers (such as hemp, jute, bamboo and sisal) and its applications which were used to substitute glass fiber.
\end{abstract}

Keywords

Natural Fiber, Polymer, Carbon, Bio Degradability, Human

\section{Introduction}

A composite material system is composed of two or more physically distinct phases whose combination produces aggregate properties that are different from those of its constituents. Composites can be very important because of its strong and stiff, yet very light in weight, so ratios of strength to weight and stiffness to weight are several times stronger than steel or aluminum and also possible to achieve combinations of properties not attainable with metals, ceramics, or polymers alone [1]. In the recent years, natural fibers reinforced composites are treated as most 
promising material in different application due to its attractive properties (Table 1).

Natural fibers are now dominate the automotive, construction and sporting industries by its superior mechanical properties. These natural fibers include flax, hemp, jute, sisal, kenaf, coir and many others [2]. The various advantages of natural fibers are low density, low cost, low energy inputs and comparable mechanical properties and also better elasticity of polymer composites reinforced with natural fibers, especially when modified with crushed fibers, embroidered and 3-D weaved fibers.

Glass Fiber Reinforced Polymer (GFRP) is a fiber reinforced polymer made of a plastic matrix reinforced by fine fibers of glass. Fiber glass is a lightweight, strong, and robust material used in different industries due to their excellent properties. Although strength properties are somewhat lower than carbon fiber and it is less stiff, the material is typically far less brittle, and the raw materials are much less expensive. Its bulk strength and weight properties are very favourable when compared to metals, and it can be easily formed using moulding processes. Nowadays, natural fibers such as sisal and jute fiber composite materials are replacing the glass and carbon fibers owing to their easy availability and cost. The use of natural fibers is improved remarkably due to the fact that the field of application is improved day by day especially in automotive industries. Nowadays, natural fiber composites have gained increasing interest due to their eco-friendly properties. A lot of work has been done by researchers based on these natural fibers. Natural fibers such as jute, sisal, silk and coir are inexpensive, abundant and renewable, lightweight, with low density, high toughness, and biodegradable. Natural fibres such as jute have the potential to be used as a replacement for traditional reinforcement materials in composites for applications which require high strength to weight ratio and further weight reduction.

This chapter includes a survey of the past research already available involving the issues of interest. It presents the research works on the hybrid composites and the effect of various parameters on the performance of composites studied by various investigators. The literature review is done based in the following points.

\section{Influence of Filler on Mechanical Properties}

Priyadarshini Tapas et al. [4] studied the physical and mechanical properties of $\mathrm{Al}_{2} \mathrm{O}_{3}$ filled jute fiber reinforced epoxy composites. They carried out experiment to identify the effect of filler on properties of composites. Jute and $\mathrm{Al}_{2} \mathrm{O}_{3}$ taken as reinforcement and epoxy as matrix, they have observed that filler makes significant changes on different properties of composites. In addition they have observed that Hardness, strength, flexural and tensile modulus increased with increase in the fiber and filler and inter laminar shear strength increased only by increasing fiber and decreased in addition of filler on composites.

A. Alavudeen et al. [5] studied the mechanical properties of woven banana fiber, kenaf fiber and banana/ kenaf hybrid fiber composites. The mechanical strength of woven banana/kenaf fiber hybrid composites increases due to the hybridization of kenaf with banana fibers. Tensile, flexural and impact strengths of the woven hybrid composite of banana/kenaf fibers are superior to those of the individual fibers. Sodium lauryl sulfate (SLS) treatments appear to provide an additional improvement in mechanical strength through enhanced interfacial bonding. Morphological studies of fractured mechanical testing samples were performed by scanning electron microscopy (SEM) to understand the de-bonding of fiber/matrix adhesion.

Table 1. Provides information about natural fibers available in the nature in different form [3].

\begin{tabular}{|c|c|c|c|c|c|}
\hline Wood fiber & Stalk fiber & Fruit fiber & Seed fiber & Leaf fiber & Bast fiber \\
\hline Hard wood & Bamboo & Coconut & Cotton & Sisal & Rattan \\
\hline Soft wood & Wheat & Betel nut & Oil palm seed & Manila & Hemp \\
\hline \multirow[t]{7}{*}{ Saw dust } & Rice & & Kapok & Banana & Jute \\
\hline & Grass & & Alfalfa & Palm & Ramic \\
\hline & Barley & & & Mengkuang & Bananna \\
\hline & Corn & & & Date palm & Flax \\
\hline & & & & Pinappile & Suger cane \\
\hline & & & & Abaka & Kenaf \\
\hline & & & & & Roselle \\
\hline
\end{tabular}


M. Ramesh et al. [6] investigated the mechanical properties of sisal, jute and glass fiber reinforced polyester composites. They observed that the addition of glass fiber into jute fiber composite resulted in maximum tensile strength. In the same way they have observed that jute and sisal mixture composites sample is capable having maximum flexural strength and maximum impact strength was obtained for the sisal fiber composite. Figure 1 shows an illustration of a composite material.

The variation of tensile strength, flexural strength and compressive strength of epoxy based sisal-glass hybrid composites has been studied by H. Ranganna et al. [5] they have observed that $2 \mathrm{~cm}$ fiber length hybrid composites showed maximum optimal tensile, flexural and compressive strength than 1 and $3 \mathrm{~cm}$. The effect of alkali treatment on the tensile flexural and compressive properties has also been studied. It is found that treated hybrid composites showed higher strength than untreated composites. Gopinath et al. [7] experimentally studies the mechanical behavior of jute fiber in polyester and epoxy matrices and the results showed that jute-polyester processing time is far lesser as compared to jute-epoxy laminate.

A. Gowthami et al. [8] developed sisal natural fiber composites with and without silica by incorporating $100 \%$ biodegradable sisal fibers as reinforcement in the polyester matrix. The results showed that the tensile strength and tensile modulus of composites with silica are 1.5 and 1.08 times greater than that of composite without silica respectively. The impact strength of composite with sand 1.36 and 1.8 times greater than that of composites without silica and plain polyester, respectively.

Amar Patnai et al. [9] studied the three body abrasive wear and mechanical properties of particulate filled glass epoxy composites. Their work aimed to study on abrasive wear behavior of randomly oriented glass fiber (RGF) reinforced with epoxy resin filled with $\mathrm{Al}_{2} \mathrm{O}_{3}$, SiC and pine bark dust. Dry sand/rubber wheel abrasion tests (RWAT) were carried out at $100 \mathrm{rpm}$ test speed. The tests were carried out at 50 and $75 \mathrm{~N}$ loads by varying the abrading distance from 200 to $600 \mathrm{~m}$. Experimental results of abrasive wear tests revealed that wear of composite was sensitive to variations of abrading distance and less sensitive to sliding velocity.

Hemalata Jena et al. [10] studied the effect of bamboo fiber composite filled with cenosphere. They have reported that the impact property of bio-fiber reinforced composite is greatly influenced by addition of cenosphere as filler and lamina. For a given laminated composite, the impact strength is increased with addition of filler up to a certain limit and after which it is decreased on further addition. The results reveal the sensitivity of the impact properties to the concentration of the fillers. Increase in lamina from 3 to 7 , the impact strength is increased and on further increasing the lamina to 9, the strength is decreased. Among all 7 layers composite with $1.5 \mathrm{wt} \%$ of cenosphere has the maximum impact strength of $18.132 \mathrm{KJ} / \mathrm{m}^{2}$. There is also seen that decrease in density of the composites which are also greatly depended on the content of fillers and fiber.

Girisha, C. et al. [11] studied the mechanical properties of composites of chemically treated fibers from husk of arecanut and fibers from the fruit of tamarind. They observed that treated fibers showed better results when compared to untreated fibers. They also noticed that the strength of the hybrid composites increases with increase in volume fraction of fiber in the hybrid composites. In the investigation arecanut fruit husk fibers and tamarind fruit fibers were reinforced with Epoxy matrix and composites have been developed by manual hand layup technique. From the experiment it was found that all the hybrid natural fiber composites shown maximum mechanical properties for $40 \%$ - $50 \%$ of the fiber reinforcements.

From [4]-[11] literature on fillers concluded that physical and mechanical characteristics of composites can be modified by adding a filler phase to the matrix body during the composite preparation. The incorporation of filler in composite is to improve mechanical and tribological properties.

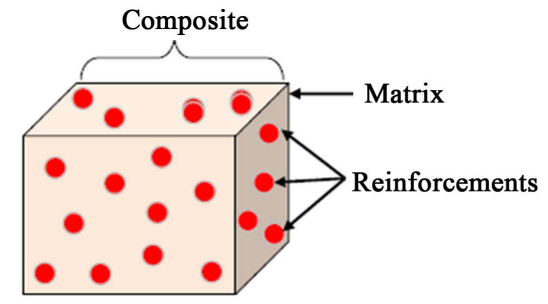

(a)

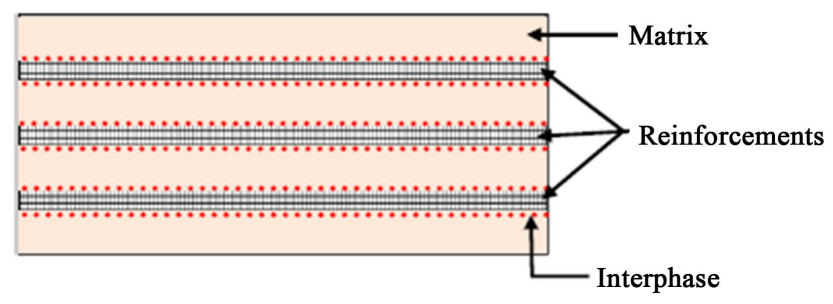

(b)

Figure 1. (a) Explains composition of laminate which include resin as a matrix and fiber as reinforcement and (b) shows inter-phase of matrix and reinforcement. 


\section{Effect of Process Parameters on Mechanical Characteristics}

Berhanu et al. [12] studies the effect of weight percentage of jute fiber reinforced in polypropylene based composites and found out that mechanical properties enhanced as the jute weight percentage increased up to $40 \%$.

D. dash et al. [13] concluded that the mechanical properties of composites such as tensile strength and compressive strength of natural fiber composite was reported and compare with the data for glass/epoxy composites. It has been seen form tensile test that bamboo composite laminates having higher tensile strength and stiffness than jute composite laminates, but not at par the glass fibre reinforced composite. Compressive test shows that compressive strength and modulus of jute composite is higher than bamboo composite, but less than glass composite the fibre orientation angle of 0/90, 15/-75, 30/-60, and 45/-45 as shown in Figure 2, on tensile behaviour were analyzed and showed that the fiber orientation of 0 provides higher strength and modulus than 45 direction of fiber orientation. The mechanical property also depends upon individual material property. The glass fiber was manufactured artificially in an industrial plant with special tool while the bamboo and jute fiber was available from nature \& manufactured by simple tool and/or manually that may result inconsistency during manufacturing of product. Due to this reason the strength of natural fibers does not come up to the level of traditional e-glass fiber. But the natural fiber reinforced composite can be used in places where light load application is important and the economics of natural fiber composite materials is more beneficial as compared to e-glass fiber composites.

S. Raghuraman et al. [14] concluded that the composite with 50\% sisal-glass fiber and 50\% resin combination has maximum tensile strength of $97.71 \mathrm{MPa}$. The breaking load of sisal-glass fiber reinforced composite is found as high $(10.285 \mathrm{KN})$. It is found that breaking load of sisal-glass fiber reinforced composite is 1.10 times higher than sisal-coir-glass fiber reinforced composite and 1.33 times higher than coir-glass fiber reinforced composite. The percentage elongation of coir-glass fiber reinforced composite is found as higher than the other composites and hence it may have more ductile property in nature. The hybrid with composite with $40 \%$ sisalcoir-glass fibers and 60\% resin combination has high flexural strength (138.87 MPa) and high impact strength $\left(1.429 \mathrm{KJ} / \mathrm{m}^{2}\right)$.

Zamri et al. [15] studied the mechanical properties of jute/glass reinforced polyester with water absorption condition. Composites are subjected to various water conditions and test were performed by immersing composite specimen in to three different water conditions, distilled water, sea water and acidic water, and water was in room temperature for a period of three weeks and also effect of the various water environments on the flexural and compression characteristics were investigated in this study. It found out that the jute composite is not suitable for underwater applications.

Onal et al. [16] studies the properties such as tensile and flexural strength of glass/carbon hybrid specimen with layer by layer sequence before impact and after impact. It is found out that carbon fire on the end surfaces increases flexural strength and also the tensile property of hybrid is better. Gujjala et al. [17] reviewed the mechanical properties of jute/glass reinforced epoxy hybrid laminate with varying hybrid sequences and pure glass, jute and epoxy composite and they were compared. Composites prepared bu using hand layup technique and
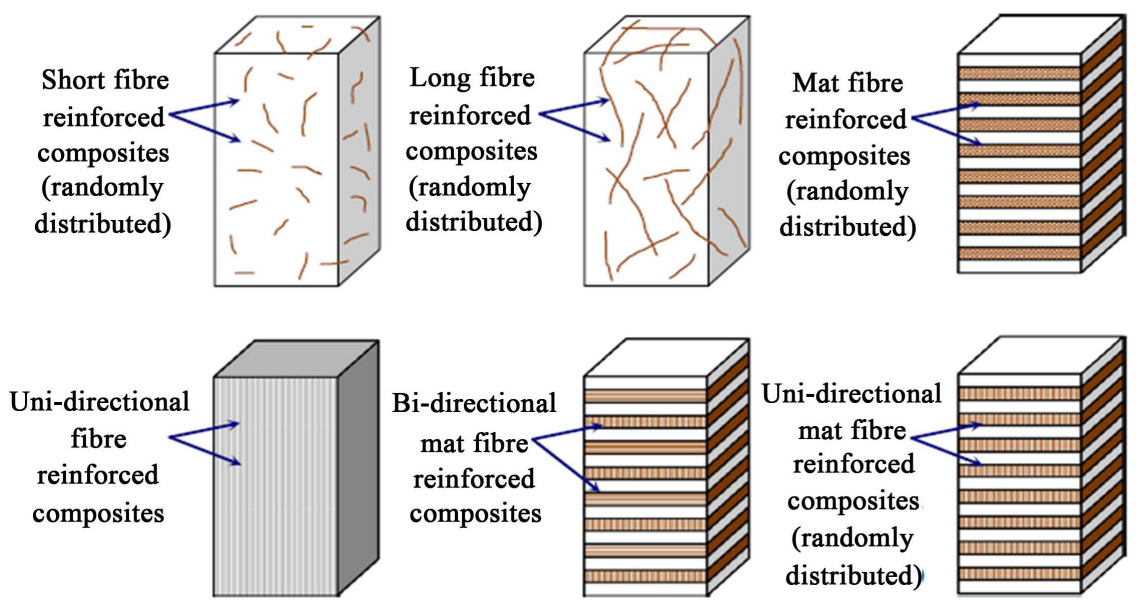

Figure 2. Different type of fiber orientation used for the laminate manufacturing. 
laminates were prepared with a total of four piles by varying the position of glass and jute. It is found out that hybrids have better properties than pure jute and epoxy alone but less than pure glass.

Sathish Pujari et al. [18] reviewed the comparison and potentiality of jute \& banana fiber composites emphasizes both mechanical and physical properties and their chemical composition. The utilization and application of the cheaper goods in high performance appliance is possible with the help of this composite technology. Combining the useful properties of two different materials, cheaper manufacturing cost, versatility etc., makes them useful in various fields of engineering, high performance applications such as leisure and sporting goods, shipping industries, aerospace etc. Hence, with this back ground, it is concluded that, the composite stands the most wanted technology in the fast growing current trend.

Tara Sen et al. [19] reviewed that the application of composites in structural facilities is mostly concentrated on increasing the strength of the structure with the help of artificial fibres and does not address the issue of sustainability of these raw materials used for strengthening purposes. In an expanding world population and with the increase of the purchasing potentials, the need for raw materials required for structural strengthening, that would satisfy the demand on world market is rapidly growing. In the Table 2 provide information about the properties of various natural fibers.

Samivel et al. [20] studied the experimentally the effect of hybridization of banana and kenaf fiber reinforced hybrid composites and found out that hybrid composites offered better resistance to water absorption as compared to un-hybrid composites. Jayabal et al. [21] investigated the effect of hybridization on mechanical properties of coir-glass hybrid laminate and found out that coir fibre (natural) fails quicker than glass fibre and incorporation of glass fibers at extreme plies enhances the mechanical properties of coir laminates.

Hind Abdellaoui et al. [22] examined the effects of number of layers and fibre directions on the mechanical behaviour of composites. The results illustrate that the mechanical behaviour of laminated has improved by increasing the number of layers. The maximal properties were obtained in case of composite at 5 layers. The composites at 0 degree fibre direction and 0 degree cutting direction have high mechanical properties than the other cases. The results show a certain difference between the measured and predicted modulus (Young modulus, shear modulus, Poisson coefficient). This difference is probably due to the perfect bonding between fibres and matrix as considered in assumptions. Yoshihiko Arao et al. [23] developed an effective process to improve the mechanical properties of jute/poly lactic acid composites. From results they noted that note that the suppression of hydrolysis is necessary to improve the overall performance. When PLA without modification against hydrolysis was used, addition of jute fiber increased the modulus but lowered the absolute tensile strength.

Ahmed and Mohammad et al. [24] revealed the theoretical dynamic analysis of Reinforced Concrete slab under free-free and simply supported condition. They showed that there is an influence of the support on the modal properties as the values are high in simply supported condition than other. Hence for experimental analysis freefree condition gives the accurate modal properties. Ratnaparkhi et al. [25] studied the dynamic properties by experimental and FEA simulation of glass/epoxy reinforced hybrid composite under free-free condition with different aspect ratio and the ply orientation. Here the result show that the increase in aspect ratio leads to increase of natural frequency and increase of ply orientation about [45/-45] and [30/60] leads to decrease of natural frequency. From [11]-[25] literature concluded that fabrication of composites mainly influenced on the properties of the composites. The mechanical properties such as tensile, flexural and impact strength can be modified by fabricating the composites using different techniques. Figure 3 shows varieties of natural fibers which are produced by plants.

\begin{tabular}{|c|c|c|c|c|}
\hline Fibre type & Density $\mathrm{Kg} / \mathrm{m}^{3}$ & Water absorption \% & Modulus of elasticity E (GPa) & Tensile strength (MPa) \\
\hline Sisal & $800-700$ & 56 & 15 & 268 \\
\hline Roselle & $800-750$ & $40-50$ & 17 & $170-350$ \\
\hline Banana & $950-750$ & 60 & 23 & $180-430$ \\
\hline Date palm & 463 & $60-65$ & 70 & $125-200$ \\
\hline cocounut & $145-380$ & $130-180$ & $19-26$ & $120-200$ \\
\hline Reed & 490 & 100 & 37 & $70-140$ \\
\hline
\end{tabular}




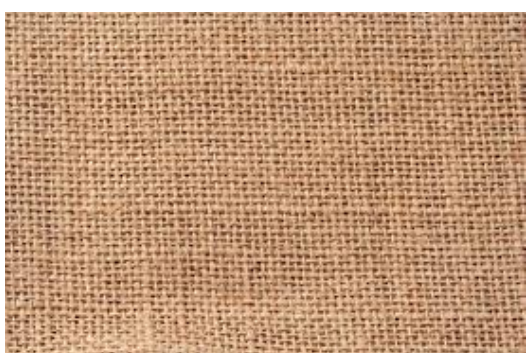

JUTE

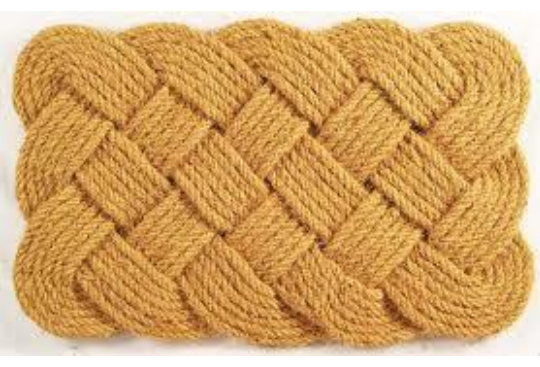

COIR

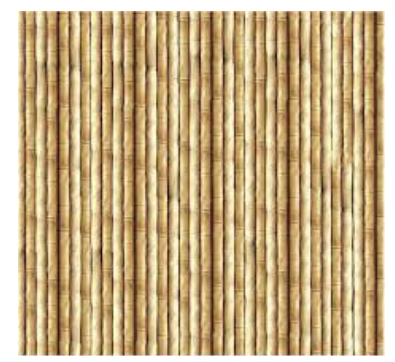

BAMBOO

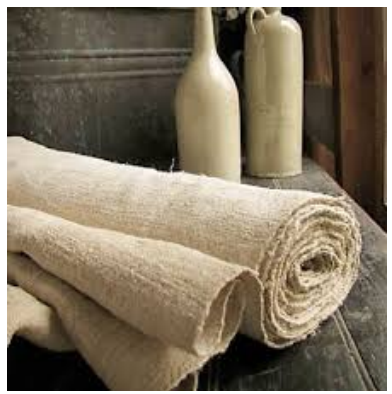

HEMP

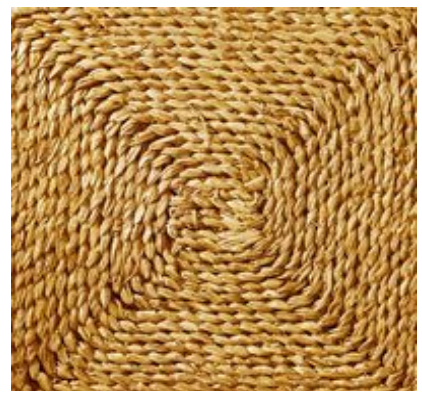

SISAL

Figure 3. Varieties of Natural Fiber which are produced by plants.

\section{Conclusions}

The usage of natural fiber as reinforcement in polymer composites was inspected from the outlook of position and expectations of natural fibers, fabrication and characterization of natural fiber, fiber surface refitting using different fillers and properties change in the natural fiber based polymer composite. Comparing natural fiber and glass fiber reinforced composites found that natural fibers were superior in industrial application. Moreover, due to the usage of natural fibers in different engineering application and construction industries, it provides way for economic development in rural areas.

The results in the investigation indicate that, there is a possibility to enhance the properties of jute fiber reinforced polyester composites. But very few investigations carried on jute/glass fiber reinforced epoxy composites and properties. Literature showed that there was no much information available on modal test method to find the dynamic properties of the composites. Development of a suitable hybrid with a known stacking sequence will have applications in automotive industry for weight and cost reduction; this leads way for the investigation on mechanical and dynamic properties of jute/glass fiber reinforced epoxy hybrid composites by using both static test methods and dynamic test methods and validating the results through FE simulation.

\section{References}

[1] Malhotra, N., Sheikh, K. and Rani, S. (2012) A Review on Mechanical Characterization of Natural Fiber Reinforced Polymer Composites. Journal of Engineering Research and Studies, 3, 75-80.

[2] Samuel, O.D., Agbo, S. and Adekanye, T.A. (2012) Assessing Mechanical Properties of Natural Fibre Reinforced Composites for Engineering Applications. Journal of Minerals and Materials Characterization and Engineering, 11, 780-784. http://dx.doi.org/10.4236/jmmce.2012.118066

[3] Chandramohan, D. and Marimuthu, K. (2011) A Review on Natural Fibers. IJRRAS, 8, 194-206.

[4] Swain, P.T.R. and Biswas, S. (2014) Physical and Mechanical Behavior of $\mathrm{Al}_{2} \mathrm{O}_{3}$ Filled Jute Fiber Reinforced Epoxy Composites. International Journal of Current Engineering and Technology, 2, 67-71. http://dx.doi.org/10.14741/ijcet/spl.2.2014.13

[5] Alavudeen, A., Rajini, N., Karthikeyan, S., Thiruchitrambalam, M. and Venkateshwaren, N. (2015) Mechanical Properties of Banana/Kenaf Fiber-Reinforced Hybrid Polyester Composites: Effect of Woven Fabric and Random Orientation. Materials and Design, 66, 246-257. http://dx.doi.org/10.1016/j.matdes.2014.10.067

[6] Ramesh, M., Palanikumar, K. and Reddy, K.H. (2013) Mechanical Property Evaluation of Sisal-Jute-Glass Fiber Reinforced Polyester Composites. Composites: Part B, 48, 1-9. http://dx.doi.org/10.1016/j.compositesb.2012.12.004 
[7] Gopinath, A., Senthil Kumar, M. and Elayaperumal, A. (2014) Experimental Investigations on Mechanical Properties of Jute Fiber Reinforced Composites with Polyester and Epoxy Resin Matrices. 12th Global Congress on Manufacturing and Management, GCMM 2014, Procedia Engineering.

[8] Gowthami, A., Ramanaiah, K., Prasad, A.V.R., Reddy, K.H.C. and Rao, K.M. (2012) Effect of Silica on Thermal and Mechanical Properties If Sisal Fiber Reinforced Polyster Composites. Journal of Material Environment Science, 4, 199-204.

[9] Patnaik, A., Satapathy, A. and Biswas, S. (2011) Investigation on Three-Body Abrasive Wear and Mechanical Properties of Particulate Filled Glass Epoxy Composites. Malaysian Polymer Journal, 5, 37-40.

[10] Jena, H., Pandit, M.Ku. and Pradhan, A.Ku. (2012) Study the Impact Property of Laminated Bamboo-Fiber Composite Filled with Cenosphere. International Journal of Environmental Science and Development, 3, 456-459. http://dx.doi.org/10.7763/IJESD.2012.V3.266

[11] Sanjeevamurthy, G.C., Rangasrinivas, G. and Manu, S. (2012) Mechanical Performance of Natural Fiber-Reinforced Epoxy-Hybrid Composites. International Journal of Engineering Research and Applications (IJERA), 2, 615-619.

[12] Berhanu, T., Kumar, P. and Singh, I. (2014) Mechanical Behaviour of Jute Fibre Reinforced Polypropylene Composites. 5th International \& 26th All India Manufacturing Technology, Design and Research Conference (AIMTDR 2014), Guwahati, 12-14 December 2014.

[13] Dash, D., Samanta, S., Gautam, S.S. and Murlidhar, M. (2013) Mechanical Characterizations of Natural Fiber Reinforced Composite Materials. Advanced Materials Manufacturing \& Characterization, 3.

[14] Chaitanyan, C. and Raghuraman, S. (2013) A Study of Mechanical Properties of Sisal-Glass Reinforced Hybrid Composites. IJARSET, 6, 1-6.

[15] Zamri, M.H., Akil, H.M., Bakar, A.A., Ishak, Z.A.M. and Cheng, L.W. (2012) Effect of Water Absorption on Pultruded Jute/Glass Fiber-Reinforced Unsaturated Polyester Hybrid Composites. Journal of Composite Materials, 46, 5161. http://dx.doi.org/10.1177/0021998311410488

[16] Onal, L. and Adanur, S. (2002) Effect of Stacking Sequence on the Mechanical Properties of Glass-Carbon Hybrid Composites before and after Impact. Journal of Industrial Textiles, 31, 255-271.

[17] Gujjala, R., Ojha, S., Acharya, S.K. and Pal, S.K. (2013) Mechanical Properties of Woven Jute-Glass Hybrid-Reinforced Epoxy Composite. Journal of Composite Materials.

[18] Pujari, S., Ramakrishna, A. and Suresh Kumar, M. (2014) Comparison of Jute and Banana Fiber Composites: A Review. International Journal of Current Engineering and Technology.

[19] Sen, T. and Jagannatha Reddy, H.N. (2011) Application of Sisal, Bamboo, Coir and Jute Natural. International Journal of Innovation, Management and Technology, 2, 186-191.

[20] Samivel, P. (2013) Mechanical Behavior of Stacking Sequence in Kenaf and Bananafiber Reinforced-Polyester Laminate. IJSSIR, 2.

[21] Jayabal, S., Natarajan, U. and Sathiyamurthy, S. (2011) Effect of Glass Hybridization and Stacking Sequence on Mechanical Behaviour of Interply Coir-Glass Hybrid Laminate. Bulletin of Materials Science, 34, 293-298. http://dx.doi.org/10.1007/s12034-011-0081-9

[22] Abdellaoui, H., Bensalah, H., Echaabi, J., Bouhfid, R. and Qaiss, A. (2015) Fabrication, Characterization and Modelling of Laminated Composites Based on Woven Jute Fibres Reinforced Epoxy Resin. Materials and Design, 68, 104113. http://dx.doi.org/10.1016/j.matdes.2014.11.059

[23] Arao, Y., Fujiura, T., Itani, S. and Tanaka, T. (2015) Strength Improvement in Injection-Molded Jute-Fiber-Reinforced Polylactide Green-Composites. Composites Part B: Engineering, 68, 200-206. http://dx.doi.org/10.1016/j.compositesb.2014.08.032

[24] Ahmed, M.S. and Mohammad, F.A. (2014) Theoretical Modal Analysis of Freely and Simply Supported RC Slabs. International Journal of Mechanical, Aerospace, Industrial and Mechatronics Engineering, 8, 2026-2030.

[25] Ratnaparkhi, S.U. and Sarnobat, S.S. (2013) Vibration Analysis of Composite Plate. International Journal of Modern Engineering Research (IJMER), 3, 377-380. 